\title{
First absolute seasonal temperature estimates for greenhouse climate from clumped isotopes in bivalve shells
}

Niels de Winter ( $\nabla_{\text {n.j.dewinter@uu.nl })}$

Universiteit Utrecht https://orcid.org/0000-0002-1453-5407

Inigo Müller

Universiteit Utrecht

Ilja Kocken

Universiteit Utrecht https://orcid.org/0000-0003-2196-8718

Nicolas Thibault

Universiteit Utrecht

Clemens Ullmann

Universiteit Utrecht

Alex Farnsworth

University of Bristol

Daniel Lunt

University of Bristol

Philippe Claeys

Vrije Universiteit Brussel

Martin Ziegler

Universiteit Utrecht

\section{Article}

Keywords: temperatures, controversial, greenhouse, climates

Posted Date: January 4th, 2021

DOl: https://doi.org/10.21203/rs.3.rs-128320/v1

License: (c) (i) This work is licensed under a Creative Commons Attribution 4.0 International License. Read Full License

Version of Record: A version of this preprint was published at Communications Earth \& Environment on June 10th, 2021. See the published version at https://doi.org/10.1038/s43247-021-00193-9. 



\section{First absolute seasonal temperature estimates for greenhouse \\ 2 climate from clumped isotopes in bivalve shells}

3 Niels J. de Winter ${ }^{1,2 *}$, Inigo A. Müller ${ }^{1}$, Ilja J. Kocken ${ }^{1}$, Nicolas Thibault ${ }^{3}$, Clemens V.

$4 \quad$ Ullmann $^{4}$, Alex Farnsworth ${ }^{5}$, Daniel J. Lunt ${ }^{5}$, Philippe Claeys ${ }^{2}$, Martin Ziegler ${ }^{1}$

$5 \quad{ }^{1}$ Department of Earth Sciences, Faculty of Geosciences, Utrecht University, the Netherlands

$6 \quad{ }^{2}$ AMGC research group, Vrije Universiteit Brussel, Brussels, Belgium

$7 \quad{ }^{3}$ Faculty of Science, IGN, University of Copenhagen, Denmark

$8{ }^{4}$ Camborne School of Mines and Environment and Sustainability Institute, University of Exeter,

$9 \quad U K$

$10 \quad{ }^{5}$ School of Geographical Sciences, University of Bristol, UK.

12 *Corresponding author

14 ABSTRACT

15 Seasonal variability in sea surface temperatures plays a fundamental role in climate dynamics and

16 species distribution. As such, it is essential to better understand seasonal variability in climates of

17 the past. Previous reconstructions of seasonality in deep time are poorly constrained, relying on

18 controversial assumptions such as estimates of seawater composition and neglect seasonal bias.

19 This work presents the first absolute seasonal temperature reconstructions based on clumped

20 isotope measurements in bivalve shells which, critically, do not rely on these assumptions. Our

21 new approach reconstructs highly precise higher mid-latitude $\left(\sim 50^{\circ} \mathrm{N}\right)$ monthly temperatures from

22 individual oyster and rudist shells of the Campanian (78 million years ago) greenhouse period

23 (15-27 ${ }^{\circ} \mathrm{C}$ seasonal range). Our analysis demonstrates that seasonal bias and previous

24 assumptions about sea water oxygen isotope composition can lead to highly inaccurate temperature

25 reconstructions, distorting our understanding of the behavior of greenhouse climates and our 
ability to model them. Our results agree with fully coupled climate model simulations showing

27 greenhouse climates outside the tropics were warmer and more seasonal than previously thought.

29 MAIN

Introduction

Seasonal extremes were of vital importance for the evolution and distribution of life over

32 geological history ${ }^{1}$. The effects of greenhouse warming on seasonal variability in temperature and

33 the hydrological cycle are still poorly constrained, while being of considerable interest for 34 projecting future climate and its impact on the ongoing biodiversity crisis $^{2,3}$. Reconstructions of 35 deep time (pre-Quaternary) greenhouse periods yield valuable insights into the dynamics of warm 36 climates and the ecological response to forcing mechanisms such as rising atmospheric $\mathrm{CO}_{2}$ 37 levels ${ }^{4,5}$. Accurate reconstructions are imperative to evaluate climate model predictions under 38 dissimilar climate states ${ }^{6}$, in particular seasonal range for which there is little quantitative evidence 39 to constrain climate model behavior. The warm, ice free Late Cretaceous period presents a valuable 40 reference to assess seasonal variability under greenhouse conditions ${ }^{7,8}$.

41 Reconstructions based on stable oxygen isotope ratios $\left(\delta^{18} \mathrm{O}_{c}\right)$ in marine carbonates and 42 organic paleothermometry (e.g. TEX 86 ) indicate that Late Cretaceous global mean sea surface 43 temperatures (SST) were $\sim 5-6^{\circ} \mathrm{C}$ warmer than today with a reduced latitudinal temperature 44 gradient (an "equable climate",), while exhibiting limited temperature seasonality",10,11,12. 45 However, the reliability of past seasonal reconstructions is undermined by poorly constrained 46 assumptions. This hampers our understanding of past warm climates and hinders accurate 47 evaluation of climate models ${ }^{13,14}$. Two potentially significant biases resulting from assumptions 
underlying SST reconstructions are seasonal bias and bias resulting from assumed seawater 49 composition $\left(\delta^{18} \mathrm{O}_{\mathrm{sw}}\right.$ bias $)$.

Seasonal bias occurs if a proxy is interpreted as representing annual mean conditions but is

51 in fact biased to a particular season. Since fossil species producing the material that constitutes

52 SST archives may not have a close modern relative for proxy calibration ${ }^{16}$, uncertainties about

53 their growth seasons may unpredictably bias reconstructions. This bias limits our understanding

54 of the behavior of greenhouse climates, which further leads to misinterpretation of model-data

55 comparisons of past warm climates ${ }^{15}$ and hinders the use of paleoclimate data for informing future

56 climate predictions. Seawater oxygen isotope composition $\left(\delta^{18} \mathrm{O}_{\mathrm{sw}}\right)$ forms an important input

57 parameter into the widely used carbonate $\delta^{18} \mathrm{O}_{c}$ temperature proxy ${ }^{17}$, but remains poorly 58 constrained across geological timescales ${ }^{18,19}$. Biases in assumed $\delta^{18} \mathrm{O}_{\mathrm{sw}}$ composition thus 59 undermine SST reconstructions.

The advent of carbonate clumped isotope $\left(\Delta_{47}\right)$ SST reconstructions on a seasonal scale 61 promises to eliminate these two biases ${ }^{20}$. The clumped isotope thermometer yields accurate SST 62 reconstructions independent of $\delta^{18} \mathrm{O}_{\mathrm{sw}}$ assumptions ${ }^{21,22}$. This technique also allows the 63 reconstruction of $\delta^{18} \mathrm{O}_{\mathrm{sw}}$, yielding information about the (local) hydrological cycle, an important 64 aspect of climate rarely constrained in deep time, and rectifying bias in the popular carbonate $\delta^{18} \mathrm{O}_{c}$ 65 temperature proxy. Recent advances in clumped isotope instrumentation and standardization have 66 reconciled previous inter-lab disagreements and shown that many carbonate paleoarchives (e.g. 67 foraminifera, bivalves and eggshells) conform to the theoretical $\Delta_{47}$ temperature calibration ${ }^{23,24}$ 68 (see Supplementary Methods and Discussion). The large sample sizes required for individual $69 \Delta 47$-based temperature estimates ( $>2 \mathrm{mg}$ ) have complicated paleoseasonality reconstructions using 
70 this accurate method ${ }^{25}$, but a recently developed statistical approach enables its use for seasonality 71 reconstructions ${ }^{20}$.

Here we use clumped isotope analyses on microsampled $(\sim 100 \mu \mathrm{g})$ profiles through fossil

73 bivalve shells to obtain, for the first time, absolute SST and $\delta^{18} \mathrm{O}_{\mathrm{sw}}$ seasonality reconstructions of

74 a greenhouse climate. We apply this new method on well-preserved oyster (Rastellum diluvianum 75 and Acutostrea incurva) and rudist (Biradiolites suecicus) shells from Campanian (78.1 $\left.\pm 0.3 \mathrm{Ma}^{26}\right)$ 76 coastal localities of the Kristianstad Basin in southern Sweden $\left(46 \pm 3^{\circ} \mathrm{N}\right.$ paleolatitude ${ }^{27}$; see Fig. 1 77 and METHODS). We further supplement these reconstructions with fully coupled climate model 78 simulations of the Campanian greenhouse (see METHODS) to explore their implications for the 79 “equable climate" hypothesis.

80

81

\section{Results}

All specimens showed clear seasonal $\delta^{18} \mathrm{O}_{\mathrm{c}}$ fluctuations of $-2.0-0.0 \%$ in $R$. diluvianum, $2.0-0.0 \%$ in $A$. incurva and $-2.7 \%{ }^{--}-1.0 \%$ in $B$. suecicus on which shell chronologies were based (see Methods). The assumption that periodic $\delta^{18} \mathrm{O}_{c}$ fluctuations reflect seasonality is demonstrated to be a valid basis for constructing intra-shell chronologies in nearly all modern environments ${ }^{20}$. Seasonal $\delta^{18} \mathrm{O}_{\mathrm{c}}$ patterns show that the specimens record 3 (A. incurva and B. suecicus) to 6 ( $R$. diluvianum) full years of growth. Clumped isotope analyses on small aliquots yielded $\Delta_{47}$ ranges between $0.62-0.73 \%$ for $R$. diluvianum, $0.64-0.76 \%$ for $A$. incurva and $0.63-0.75 \%$ for $B$. suecicus. Summaries of measurement results are displayed in Table 1.

Detailed step-by-step results of the data processing routine are shown in Supplementary Methods and ${ }^{20}$. Fig. 2 and Table 1 show monthly $\Delta_{47}$, SST and $\delta^{18} \mathrm{O}_{\text {sw }}$ reconstructions for each specimen. Uncertainties at the $95 \%$ confidence level on monthly SST vary between 1.8 and $4.2^{\circ} \mathrm{C}$ 
owing to variable monthly sampling density related to intra-shell growth rate variability (Fig. 2). While growth rate varied through the year (Fig. 2A), all monthly time bins in each specimen contained enough datapoints to allow separate monthly SST and $\delta^{18} \mathrm{O}_{\text {sw }}$ reconstructions. Calculations of mean annual temperature (MAT) and seasonality from these monthly averages eliminates seasonal bias due to growth rate variability. Statistically significant $(\mathrm{p}<0.01)$ SST seasonality was observed in all specimens. Summer and winter temperatures, defined as mean temperatures of the warmest and coldest month, in A. incurva $\left(13 \pm 2-26 \pm 4^{\circ} \mathrm{C}\right)$ and B. suecicus $\left(14 \pm 4-25 \pm 3^{\circ} \mathrm{C}\right)$ are statistically indistinguishable $(\mathrm{p}>0.2)$, while SST from $R$. diluvianum are significantly higher $\left(20 \pm 2-29 \pm 2^{\circ} \mathrm{C} ; \mathrm{p}<0.05\right)$. Significant $\delta^{18} \mathrm{O}_{\mathrm{sw}}$ seasonality was found in $R$. diluvianum $(0.0 \pm 0.3-1.1 \pm 0.3 \%$ VSMOW; $<<0.01)$ and B. suecicus $(-1.8 \pm 0.8-0.6 \pm 0.5 \%$ VSMOW; $\mathrm{p}<0.01)$, but not in A. incurva $(-0.9 \pm 0.2--0.4 \pm 0.9 \% \mathrm{VSMOW}$; $=0.07$; Fig. 2; Table 1). $R$. diluvianum records significantly higher $\delta^{18} \mathrm{O}_{\mathrm{sw}}$ values $(\mathrm{p}<0.01)$ than the other specimens. In all specimens, monthly $\delta^{18} \mathrm{O}_{\text {sw }}$ positively correlates with monthly SST (see Fig. 2).

We compare our reconstructed SST with local and global Campanian SSTs modelled using the HadCM3L model, one of the most developed paleoclimate models to date and part of the IPCC intercomparison assessment reports ${ }^{6,14}$. We present global Campanian latitudinal gradients in summer, winter and MAT (Fig. 3A) as well as monthly SST in the Boreal Chalk Sea (Fig. 3B) for both $2 \times$ and $4 \times$ preindustrial atmospheric $\mathrm{pCO}_{2}$ simulations (see Methods). Model results are summarized in Supplementary Data 5. The modelled Campanian latitudinal SST gradient (difference between tropics and high-latitude MAT; $26^{\circ} \mathrm{C}$ in both simulations) resembles the modern $\left(25^{\circ} \mathrm{C}\right.$ gradient). Modelled global mean Campanian SST seasonality (difference between warmest and coldest month) is lower $\left(6.6^{\circ} \mathrm{C}\right)$ than that of the modern ocean $\left(8.6^{\circ} \mathrm{C}\right)$ under $2 \times$ preindustrial $\mathrm{pCO}_{2}$ conditions and similar to the present $\left(8.2^{\circ} \mathrm{C}\right)$ in the $4 \times$ preindustrial $\mathrm{pCO}_{2}$ 
116 simulation, in disagreement with the hypothesis of reduced seasonality during greenhouse

117 conditions. Campanian modelled MAT is $\sim 18^{\circ} \mathrm{C}$ and $\sim 22^{\circ} \mathrm{C}$ under $2 \times$ and $4 \times$ preindustrial

118 atmospheric $\mathrm{pCO}_{2}$, respectively, compared to $\sim 14^{\circ} \mathrm{C}$ in the modern ocean (NOAA, 2020), yielding

119 an equilibrium climate sensitivity, or global warming per doubling of atmospheric $\mathrm{CO}_{2}$

120 concentration, of $\sim 4^{\circ} \mathrm{C}^{15}$. Specifically, simulated seasonal SST ranges in the Campanian

121 Kristianstad Basin of $7 \pm 3-20 \pm 2^{\circ} \mathrm{C}$ and $12 \pm 2-26 \pm 2^{\circ} \mathrm{C}$ for $2 \times$ and $4 \times$ preindustrial atmospheric

$122 \mathrm{pCO}_{2}$ forcing, respectively, are significantly warmer than in present day southern Sweden $(3 \pm 0.8-$

$\left.123 \quad 17 \pm 0.4^{\circ} \mathrm{C}^{28}\right)$.

124

125

\section{Discussion}

126

Our novel $\Delta_{47}$-based monthly SST and $\delta^{18} \mathrm{O}_{\mathrm{sw}}$ reconstructions from $A$. incurva and $B$.

127 suecicus are statistically indistinguishable from $4 \times$ preindustrial $\mathrm{pCO}_{2}$ simulations $(\mathrm{p}>0.05)$ and

128 significantly warmer than the $2 \times$ preindustrial $\mathrm{pCO}_{2}$ simulations $\left(>4^{\circ} \mathrm{C}\right.$ higher $\left.\mathrm{MAT}, \mathrm{p}<0.05\right)$ of

129 local SST seasonality (p>0.05; Fig. 3). Higher $(\mathrm{p}<0.05)$ SST $\left(+4-5^{\circ} \mathrm{C}\right)$ and $\delta^{18} \mathrm{O}_{\mathrm{sw}}(+1.0-1.5 \%$ ) in

$130 R$. diluvianum are likely caused by local differences in its shallower, inter-tidal $(<5 \mathrm{~m})$

131 environment ${ }^{27}$. Temporary areal exposure during low tides could have elevated temperatures and

$132 \delta^{18} \mathrm{O}_{\text {sw }}$ recorded in $R$. diluvianum year-round by direct sunlight and evaporation, as in modern

133 inter-tidal oyster species ${ }^{29}$. By comparison, the deeper (5-15m) subtidal environments of $A$.

134 incurva and B. suecicus were unaffected by these processes and may have received more water

135 with an open marine $\delta^{18} \mathrm{O}_{\mathrm{sw}}$ signature (closer to the $-1 \% \mathrm{VSMOW}$ assumed for the ice-free

136 Cretaceous ${ }^{30}$ ), especially in winter. These local environmental differences are not resolved in the

137 climate model simulations but show the unprecedented detail of local SST and $\delta^{18} \mathrm{O}_{\text {sw }}$

138 reconstructions from clumped isotope analyses on bivalve shells (see Supplementary 
139 Discussion). The $\sim 1 \%$ o $\delta^{18} \mathrm{O}_{\text {sw }}$ seasonality shows that summers in the Campanian Kristianstad 140 Basin either experienced excess evaporation, which increases $\delta^{18} \mathrm{O}_{\mathrm{sw}}$ by preferentially removing 141 isotopically light seawater, or reduced precipitation, which supplies isotopically light meteoric 142 water, reducing $\delta^{18} \mathrm{O}_{\mathrm{sw}}$. Both processes lead to comparatively dry summers and wet winters. Strong seasonal fluctuations in $\delta^{18} \mathrm{O}_{\text {sw }}$ (up to $1.3 \%$ in B. suecicus) and regular deviations 144 from the commonly assumed -1\%oVSMOW $\delta^{18} \mathrm{O}_{\mathrm{sw}}$ value $\mathrm{e}^{26}$ lead to large differences (up to $8.9^{\circ} \mathrm{C}$ 145 in $R$. diluvianum) between SST estimates based on $\Delta_{47}$ and the widely used $\delta^{18} \mathrm{O}_{c}$ proxy (Fig. 2). 146 The risk of assuming constant $\delta^{18} \mathrm{O}_{\text {sw }}$ is even more clearly illustrated by significantly $\left(+3.5-6.0^{\circ} \mathrm{C}\right)$ 147 higher $\delta^{18} \mathrm{O}_{\mathrm{c}}$-based seasonal temperature reconstructions for B. suecicus compared to A. incurva, 148 while both specimens grew under similar SST seasonality conditions (Fig. 2B). Similarly, $\delta^{18} \mathrm{O}_{\mathrm{c}^{-}}$ 149 based temperature reconstructions of $A$. incurva and $R$. diluvianum are indistinguishable, while the 150 paleoenvironment of $R$. diluvianum was $4-5^{\circ} \mathrm{C}$ warmer year-round (Fig. 2B), illustrating that the 151 constant $\delta^{18} \mathrm{O}_{\text {sw }}$ assumption is only valid in settings with negligible $\delta^{18} \mathrm{O}_{\text {sw }}$ seasonality and where $152 \delta^{18} \mathrm{O}_{\text {sw }}$ is known. Low-latitude Tethyan SST seasonality reconstructions based on rudist $\delta^{18} \mathrm{O}_{\mathrm{c}}{ }^{10}$ 153 agree with model simulations, which may indicate that $\delta^{18} \mathrm{O}_{\text {sw }}$ seasonality is less important in open 154 marine settings, although data-model agreement is by no means solid evidence for correct $\delta^{18} \mathrm{O}_{\text {sw }}$ 155 assumptions, which should always be independently verified (Fig. 3A). Our findings corroborate 156 previous $\Delta 47$-based and proxy comparison studies which also report a significant cold bias $\left(\sim-8^{\circ} \mathrm{C}\right)$ 157 in $\delta^{18} \mathrm{O}_{\mathrm{c}}$-based SST reconstructions due to inaccurate $\delta^{18} \mathrm{O}_{\mathrm{sw}}$ assumptions ${ }^{8,31}$. However, these 158 studies did not account for seasonal biases. of bio-archives can lead to significant biases in MAT reconstructions compared to our more accurate estimates of MAT as an average of $\Delta_{47}$-based monthly SST. In this case, slower summer 
162 and autumn growth (months 4-7 in Fig. 2A), especially in A. incurva and B. suecicus, would cause

163 bulk analysis of shell material to underestimate MAT. Indeed, our Campanian mid-latitude SST

164 ranges $\left(\sim 15-27^{\circ} \mathrm{C}\right.$, MAT of $\left.20^{\circ} \mathrm{C}\right)$ are significantly higher than previous reconstructions of the 165 same paleolatitude based on fish tooth $\delta^{18} \mathrm{O}_{\mathrm{c}}\left(15-20^{\circ} \mathrm{C}^{11}\right)$, chalk $\delta^{18} \mathrm{O}_{\mathrm{c}}\left(12-15^{\circ} \mathrm{C}^{12}\right)$, bulk mollusk $166 \Delta_{47}\left(5-12^{\circ} \mathrm{C}^{32}\right), \mathrm{TEX}_{86}\left(15-20^{\circ} \mathrm{C}^{8}\right)$ and sub-annual mollusk $\delta^{18} \mathrm{O}_{\mathrm{c}}\left(15-22^{\circ} \mathrm{C}^{10,26}\right.$; Fig. 3A). All 167 these reconstructions are potentially affected by either seasonal or $\delta^{18} \mathrm{O}_{\mathrm{sw}}$ bias, or both. Our more 168 accurate reconstructions of $\delta^{18} \mathrm{O}_{\mathrm{sw}}$ and SST on a seasonal scale aid in evaluating these biases and 169 correct for them by combining long-term MAT reconstructions with snapshots of climate on the 170 seasonal scale.

Given the increase in frequency and duration of growth stops in modern mollusks with 172 increasing latitude ${ }^{33}$, seasonal biases are likely more common in higher latitude environments. The 173 accuracy of our new method for SST reconstruction and the remarkable agreement between $\Delta_{47-}$ 174 based SST ranges and our climate model strongly suggest that the average seasonal range 175 reconstructed from our three specimens $\left(15-27^{\circ} \mathrm{C}\right.$ range, MAT of $\left.20^{\circ} \mathrm{C}\right)$ represents the most 176 accurate SST seasonality reconstructions for the Campanian Boreal Chalk Sea to date. Since 177 shallow marine bio-archives can record local climate conditions at higher spatial and temporal 178 resolution than conventional (open ocean) archives, our monthly resolved $\Delta 47$ records showcase a 179 tool for eliminating widespread biases related to seasonal variability and $\delta^{18} \mathrm{O}_{\text {sw }}$ assumptions on 180 SST reconstructions across time and space.

181 Robust agreement between our reconstructions and the $4 \times$ preindustrial $\mathrm{pCO}_{2}$ model 182 simulation down to the monthly scale provides strong evidence for considerably warmer $\left(\sim 8^{\circ} \mathrm{C}\right)$ 183 higher latitudes during the Late Cretaceous greenhouse compared to the present day. Significant 184 disagreement of summer, winter and annual SST reconstructions from every specimen in this study 
185 with the $2 \times$ preindustrial $\mathrm{pCO}_{2}$ simulation strongly favor warmer $\left(4 \times\right.$ preindustrial $\left.\mathrm{pCO}_{2}\right)$ climate conditions (see Supplementary Data 4). Bio-archives from mid to high latitudes are likely much more sensitive to $\delta^{18} \mathrm{O}_{\mathrm{sw}}$ and seasonality bias than low-latitude records, contributing to the flawed paradigm of shallow latitudinal temperature gradients during greenhouse climates. Instead, our results concur with the recent trend of converging data and model reconstructions yielding modernscale Late Cretaceous latitudinal temperature gradients ${ }^{13}$, thereby challenging the hypothesis of “equable climate" during greenhouse periods". Moreover, our unique absolute monthly SST 192 reconstructions and model simulations corroborate growing evidence against the hypothesis of 193 reduced temperature seasonality in greenhouse climates ${ }^{30}$. Future work should aim to further test 194 these hypotheses by applying the clumped isotope seasonality method on bio-archives from a range 195 of latitudes in greenhouse climate periods. Results from B. suecicus represent the first $\Delta_{47}$-based SST reconstructions from rudist bivalves, introducing an abundant archive for accurate Mesozoic

197 SST seasonality reconstructions with which these new insights can be evaluated.

\section{Conclusions}

Our new absolute temperature seasonality reconstructions merit critical evaluation of 201 classical paleoclimate records that risk bias, such as those based on $\delta^{18} \mathrm{O}_{c}$ (assuming constant $\left.202 \delta^{18} \mathrm{O}_{\text {sw }}{ }^{7,10}\right)$, bulk analyses of fossil material with growth seasonality (e.g. mollusks and brachiopods ${ }^{31}$ ) or a fixed growth season (e.g. planktic foraminifera ${ }^{36}$ ) and organic proxies that may

204 be seasonally biased (e.g. TEX $\mathrm{TE}_{86}$ and $\mathrm{U}^{\mathrm{k}}{ }_{37}{ }^{5,37}$ ). In addition, our monthly $\delta^{18} \mathrm{O}_{\mathrm{sw}}$ reconstructions 205 for the first time allow evaluation of local seasonality in the hydrological cycle from accretionary 206 bio-archives, revealing dry summers and wet winters in the Campanian Kristianstad Basin. This 
208 unknown high-resolution variability in salinity, local rainfall and evaporation in past climates.

209 Combined with longer-term, global-scale paleoclimate records and models, our new method for

210 absolute monthly SST and $\delta^{18} \mathrm{O}_{\mathrm{sw}}$ reconstructions has the potential to resolve critical

211 disagreements between SST proxies, reduce biases of deep-time paleoclimate reconstructions,

212 shed light on new aspects of past climate seasonality and reconcile proxy reconstructions and 213 model simulations of greenhouse climate.

214

215 MAIN REFERENCES

216 1. Marshall, D. J. \& Burgess, S. C. Deconstructing environmental predictability: seasonality, 217 environmental colour and the biogeography of marine life histories. Ecology Letters 18, 174$218181(2015)$.

219 2. Matthews, T., Mullan, D., Wilby, R. L., Broderick, C. \& Murphy, C. Past and future climate 220 change in the context of memorable seasonal extremes. Climate Risk Management 11, 37-52 221 (2016).

222 3. Carré, M. \& Cheddadi, R. Seasonality in long-term climate change. Quaternaire. Revue de 223 l'Association française pour l'étude du Quaternaire 173-177 (2017)

224 doi:10.4000/quaternaire.8018.

225 4. Zeebe, R. E., Zachos, J. C. \& Dickens, G. R. Carbon dioxide forcing alone insufficient to 226 explain Palaeocene-Eocene Thermal Maximum warming. Nature Geoscience 2, 576 (2009).

227 5. Cramwinckel, M. J. et al. Synchronous tropical and polar temperature evolution in the $228 \quad$ Eocene. Nature 559, 382 (2018). 
6. IPCC. IPCC, 2013: Climate Change 2013: The Physical Science Basis. Contribution of Working Group I to the Fifth Assessment Report of the Intergovernmental Panel on Climate Change, 1535 pp. (Cambridge Univ. Press, Cambridge, UK, and New York, 2013).

7. Jenkyns, H. C., Forster, A., Schouten, S. \& Damsté, J. S. S. High temperatures in the late Cretaceous Arctic Ocean. Nature 432, 888 (2004).

8. O’Brien, C. L. et al. Cretaceous sea-surface temperature evolution: Constraints from TEX 86 and planktonic foraminiferal oxygen isotopes. Earth-Science Reviews 172, 224-247 (2017).

9. Huber, B. T., Hodell, D. A. \& Hamilton, C. P. Middle-Late Cretaceous climate of the southern high latitudes: stable isotopic evidence for minimal equator-to-pole thermal gradients. Geological Society of America Bulletin 107, 1164-1191 (1995).

10. Steuber, T., Rauch, M., Masse, J.-P., Graaf, J. \& Malkoč, M. Low-latitude seasonality of Cretaceous temperatures in warm and cold episodes. Nature 437, 1341-1344 (2005).

11. Pucéat, E. et al. Fish tooth $\delta 18 \mathrm{O}$ revising Late Cretaceous meridional upper ocean water temperature gradients. Geol 35, 107 (2007).

12. Thibault, N., Harlou, R., Schovsbo, N. H., Stemmerik, L. \& Surlyk, F. Late Cretaceous (late Campanian-Maastrichtian) sea-surface temperature record of the Boreal Chalk Sea. Climate of the Past 12, 429-438 (2016).

13. Upchurch Jr, G. R., Kiehl, J., Shields, C., Scherer, J. \& Scotese, C. Latitudinal temperature gradients and high-latitude temperatures during the latest Cretaceous: Congruence of geologic data and climate models. Geology 43, 683-686 (2015).

14. Farnsworth, A. et al. Climate Sensitivity on Geological Timescales Controlled by Nonlinear Feedbacks and Ocean Circulation. Geophys. Res. Lett. 46, 9880-9889 (2019). 
251 15. Joussaume, S. \& Braconnot, P. Sensitivity of paleoclimate simulation results to season 252 definitions. Journal of Geophysical Research: Atmospheres 102, 1943-1956 (1997).

253 16. Mosbrugger, V. Nearest-living-relative method. Encyclopedia of paleoclimatology and 254 ancient environments 607-609 (2009).

255 17. Kim, S.-T. \& O’Neil, J. R. Equilibrium and nonequilibrium oxygen isotope effects in 256 synthetic carbonates. Geochimica et Cosmochimica Acta 61, 3461-3475 (1997).

257 18. Jaffrés, J. B. D., Shields, G. A. \& Wallmann, K. The oxygen isotope evolution of 258 seawater: A critical review of a long-standing controversy and an improved geological water $259 \quad$ cycle model for the past 3.4 billion years. Earth-Science Reviews 83, 83-122 (2007).

260 19. Veizer, J. \& Prokoph, A. Temperatures and oxygen isotopic composition of Phanerozoic 261 oceans. Earth-Science Reviews 146, 92-104 (2015).

262 20. de Winter, N., Agterhuis, T. \& Ziegler, M. Optimizing sampling strategies in high263 resolution paleoclimate records. Climate of the Past Discussions 1-52 (2020) 264 doi:https://doi.org/10.5194/cp-2020-118.

265 21. Eiler, J. M. "Clumped-isotope" geochemistry-The study of naturally-occurring, 266 multiply-substituted isotopologues. Earth and Planetary Science Letters 262, 309-327 267 (2007).

268 22. Petersen, S. V. et al. Effects of Improved 170 Correction on Interlaboratory Agreement 269 in Clumped Isotope Calibrations, Estimates of Mineral-Specific Offsets, and Temperature 270 Dependence of Acid Digestion Fractionation. Geochemistry, Geophysics, Geosystems 20, $271 \quad 3495-3519$ (2019). 
272 23. Bernasconi, S. M. et al. Reducing uncertainties in carbonate clumped isotope analysis

273 through consistent carbonate-based standardization. Geochemistry, Geophysics, Geosystems

$274 \quad 19,2895-2914(2018)$.

275 24. Jautzy, J. J., Savard, M. M., Dhillon, R. S., Bernasconi, S. M. \& Smirnoff, A. Clumped

276 isotope temperature calibration for calcite: Bridging theory and experimentation.

277 Geochemical Perspectives Letters 14, 36-41 (2020).

278 25. Fernandez, A. et al. A reassessment of the precision of carbonate clumped isotope

279 measurements: implications for calibrations and paleoclimate reconstructions. Geochemistry,

280 Geophysics, Geosystems 18, 4375-4386 (2017).

281 26. de Winter, N. J. et al. Shell chemistry of the boreal Campanian bivalve Rastellum

282 diluvianum (Linnaeus, 1767) reveals temperature seasonality, growth rates and life cycle of an

283 extinct Cretaceous oyster. Biogeosciences 17, 2897-2922 (2020).

284 27. Surlyk, F. \& Sørensen, A. M. An early Campanian rocky shore at Ivö Klack, southern

$285 \quad$ Sweden. Cretaceous Research 31, 567-576 (2010).

286 28. NOAA Global Surface Temperature (NOAAGlobalTemp) data provided by the

287 NOAA/OAR/ESRL PSL, Boulder, Colorado, USA, https://psl.noaa.gov/, last accessed:

$288 \quad 28 / 05 / 2020$.

289 29. Huyghe, D. et al. New insights into oyster high-resolution hinge growth patterns. Mar $290 \quad$ Biol 166, 48 (2019).

291 30. Shackleton, N. J. Paleogene stable isotope events. Palaeogeography,

292 Palaeoclimatology, Palaeoecology 57, 91-102 (1986).

293 31. Tagliavento, M., John, C. M. \& Stemmerik, L. Tropical temperature in the Maastrichtian

294 Danish Basin: Data from coccolith $\Delta 47$ and $\delta 180$. Geology 47, 1074-1078 (2019). 
295 32. Petersen, S. V. et al. Temperature and salinity of the Late Cretaceous western interior 296 seaway. Geology 44, 903-906 (2016).

297 33. Lartaud, F. et al. A latitudinal gradient of seasonal temperature variation recorded in 298 oyster shells from the coastal waters of France and The Netherlands. Facies 56, 13 (2009).

299 34. Burgener, L., Hyland, E., Huntington, K. W., Kelson, J. R. \& Sewall, J. O. Revisiting 300 the equable climate problem during the Late Cretaceous greenhouse using paleosol carbonate 301 clumped isotope temperatures from the Campanian of the Western Interior Basin, USA. 302 Palaeogeography, Palaeoclimatology, Palaeoecology 516, 244-267 (2019).

303 35. Henkes, G. A. et al. Temperature evolution and the oxygen isotope composition of 304 Phanerozoic oceans from carbonate clumped isotope thermometry. Earth and Planetary $305 \quad$ Science Letters 490, 40-50 (2018).

306 36. Pearson, P. N. et al. Warm tropical sea surface temperatures in the Late Cretaceous and 307 Eocene epochs. Nature 413, 481-487 (2001).

308 37. Jia, G., Wang, X., Guo, W. \& Dong, L. Seasonal distribution of archaeal lipids in 309 surface water and its constraint on their sources and the TEX86 temperature proxy in 310 sediments of the South China Sea. Journal of Geophysical Research: Biogeosciences 122, $311 \quad 592-606$ (2017).

312 38. Sørensen, A. M., Surlyk, F. \& Jagt, J. W. M. Adaptive morphologies and guild structure 313 in a high-diversity bivalve fauna from an early Campanian rocky shore, Ivö Klack (Sweden). 314 Cretaceous Research 33, 21-41 (2012). 
316 Table 1: Overview of analytical results $\left(\delta^{18} O_{c}\right.$ and $\left.\Delta 47\right)$ and reconstructions

\begin{tabular}{|c|c|c|c|c|c|c|c|c|c|c|c|c|c|c|c|}
\hline \multirow{3}{*}{$\begin{array}{l}\text { Species } \\
\text { (locality) }\end{array}$} & \multicolumn{9}{|c|}{ Measurement results } & \multicolumn{6}{|c|}{ Monthly reconstructions } \\
\hline & \multirow[t]{2}{*}{$\begin{array}{l}\text { age } \\
\text { [yr] }\end{array}$} & \multicolumn{4}{|c|}{$\begin{array}{c}\delta^{18} O_{c} \\
{[\% \text { VPDB] }}\end{array}$} & \multicolumn{4}{|c|}{$\begin{array}{l}\Delta 47 \\
{[\% 0]}\end{array}$} & \multicolumn{3}{|c|}{$\begin{array}{c}\delta^{18} \mathbf{O}_{\text {sw }} \\
{[\% \text { VSMOW] }}\end{array}$} & \multicolumn{3}{|c|}{$\begin{array}{l}\text { SST } \\
{\left[{ }^{\circ} \mathbf{C}\right]}\end{array}$} \\
\hline & & $N^{\mathbf{b}}$ & min. & mean & $\max$ & $N$ & $\min$. & mean & $\max$ & $C M^{\mathrm{c}}$ & $M A^{\mathrm{d}}$ & $W M^{\mathbf{e}}$ & $C M$ & $M A$ & $W M$ \\
\hline $\begin{array}{l}R . \\
\text { diluvianum } \\
\text { (Ivö Klack) }\end{array}$ & 6.2 & 198 & $\begin{array}{l}\mathbf{- 2 . 0 8} \\
\pm 0.08\end{array}$ & $\begin{array}{r}-\mathbf{1 . 1 6} \\
\pm 0.08\end{array}$ & $\begin{array}{r}\mathbf{0 . 1 8} \\
\pm 0.08\end{array}$ & 121 & $\begin{array}{r}\mathbf{0 . 6 0 5} \\
\pm 0.077 \\
\end{array}$ & $\begin{array}{r}\mathbf{0 . 6 7 8} \\
\pm 0.077 \\
\end{array}$ & $\begin{array}{r}\mathbf{0 . 7 9 5} \\
\pm 0.077\end{array}$ & $\begin{array}{r}\mathbf{0 . 0 0} \\
\pm 0.27\end{array}$ & $\begin{array}{r}\mathbf{0 . 5 6} \\
\pm 0.11\end{array}$ & $\begin{array}{r}1.08 \\
\pm 0.36\end{array}$ & $\begin{array}{r}19.6 \\
\pm 1.8\end{array}$ & $\begin{array}{r}24.6 \\
\pm 0.7\end{array}$ & $\begin{array}{r}29.2 \\
+2.3 \\
\end{array}$ \\
\hline $\begin{array}{l}\text { A, incurva } \\
\text { (Ấsen) }\end{array}$ & 3.3 & 150 & $\begin{array}{l}-2.26 \\
\pm 0.08 \\
\end{array}$ & $\begin{array}{r}-\mathbf{0 . 7 1} \\
\pm 0.08 \\
\end{array}$ & $\begin{array}{r}\mathbf{0 . 1 5} \\
\pm 0.08 \\
\end{array}$ & 115 & $\begin{array}{r}\mathbf{0 . 6 0 1} \\
\pm 0.077 \\
\end{array}$ & $\begin{array}{r}\mathbf{0 . 7 0 6} \\
\pm 0.077 \\
\end{array}$ & $\begin{array}{r}\mathbf{0 . 8 3 1} \\
\pm 0.077 \\
\end{array}$ & $\begin{array}{r}\mathbf{- 0 . 8 9} \\
\pm 0.18 \\
\end{array}$ & $\begin{array}{r}\mathbf{- 0 . 4 6} \\
\pm 0.09 \\
\end{array}$ & $\begin{array}{r}\mathbf{- 0 . 3 6} \\
\pm 0.87 \\
\end{array}$ & $\begin{array}{r}12.7 \\
+2.3 \\
\end{array}$ & $\begin{array}{r}16.4 \\
\pm 0.7 \\
\end{array}$ & $\begin{array}{r}25.7 \\
\pm 4.2 \\
\end{array}$ \\
\hline $\begin{array}{l}\text { B. suecicus } \\
\text { (Maltesholm) }\end{array}$ & 3 & 178 & $\begin{array}{l}\mathbf{- 2 . 9 3} \\
\pm 0.08\end{array}$ & $\begin{array}{r}\mathbf{- 1 . 9 9} \\
\pm 0.08\end{array}$ & $\begin{array}{r}\mathbf{- 0 . 9 8} \\
\pm 0.08\end{array}$ & 102 & $\begin{array}{r}\mathbf{0 . 5 6 5} \\
\pm 0.077\end{array}$ & $\begin{array}{c}\mathbf{0 . 6 8 8} \\
\pm 0.077\end{array}$ & $\begin{array}{l}\mathbf{0 . 7 7 9} \\
\pm 0.077\end{array}$ & $\begin{array}{r}\mathbf{- 1 . 8 1} \\
\pm 0.78\end{array}$ & $\begin{array}{r}\mathbf{- 1 . 1 8} \\
\pm 0.17\end{array}$ & $\begin{array}{r}\mathbf{- 0 . 5 5} \\
\pm 0.45\end{array}$ & $\begin{array}{r}\mathbf{1 3 . 7} \\
\pm 3.9\end{array}$ & $\begin{array}{r}19.3 \\
\pm 0.9\end{array}$ & $\begin{array}{r}\mathbf{2 4 . 8} \\
+2.6\end{array}$ \\
\hline
\end{tabular}

$317 \mathrm{~N}=$ Number of measurements and the age is estimated from the age modelling results (Supplementary Data 1), CM =

318 Coldest Month, $\mathrm{MA}=$ Mean Annual, $\mathrm{WM}=$ Warmest Month. All uncertainties are given as $95 \%$ confidence levels. 


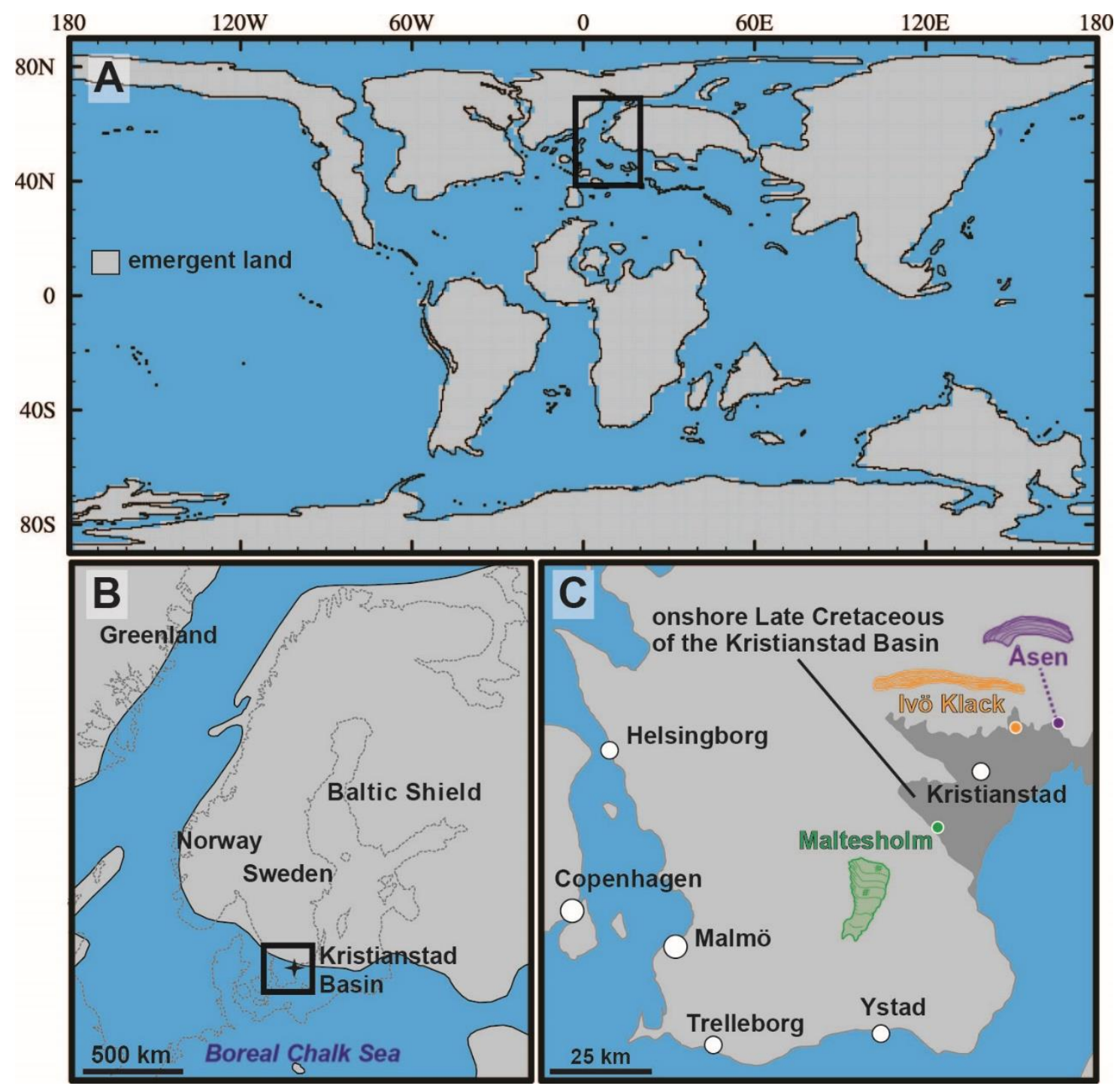

320 Fig. 1: Campanian (78 Ma) paleogeography and geological setting A) Global paleogeography used in climate model ${ }^{14}$ B) Northern Europe, black star indicates the Kristianstad Basin C)

322 Southern Sweden with Kristianstad Basin (in dark grey, submerged in the Campanian). Colored 323 dots indicate the three sampled localities on the paleoshoreline with schematic representations of 324 the species. In all maps, blue color indicates sea surface and light grey indicates emergent land. 325 Maps B) and C) are adapted from ${ }^{38}$. 

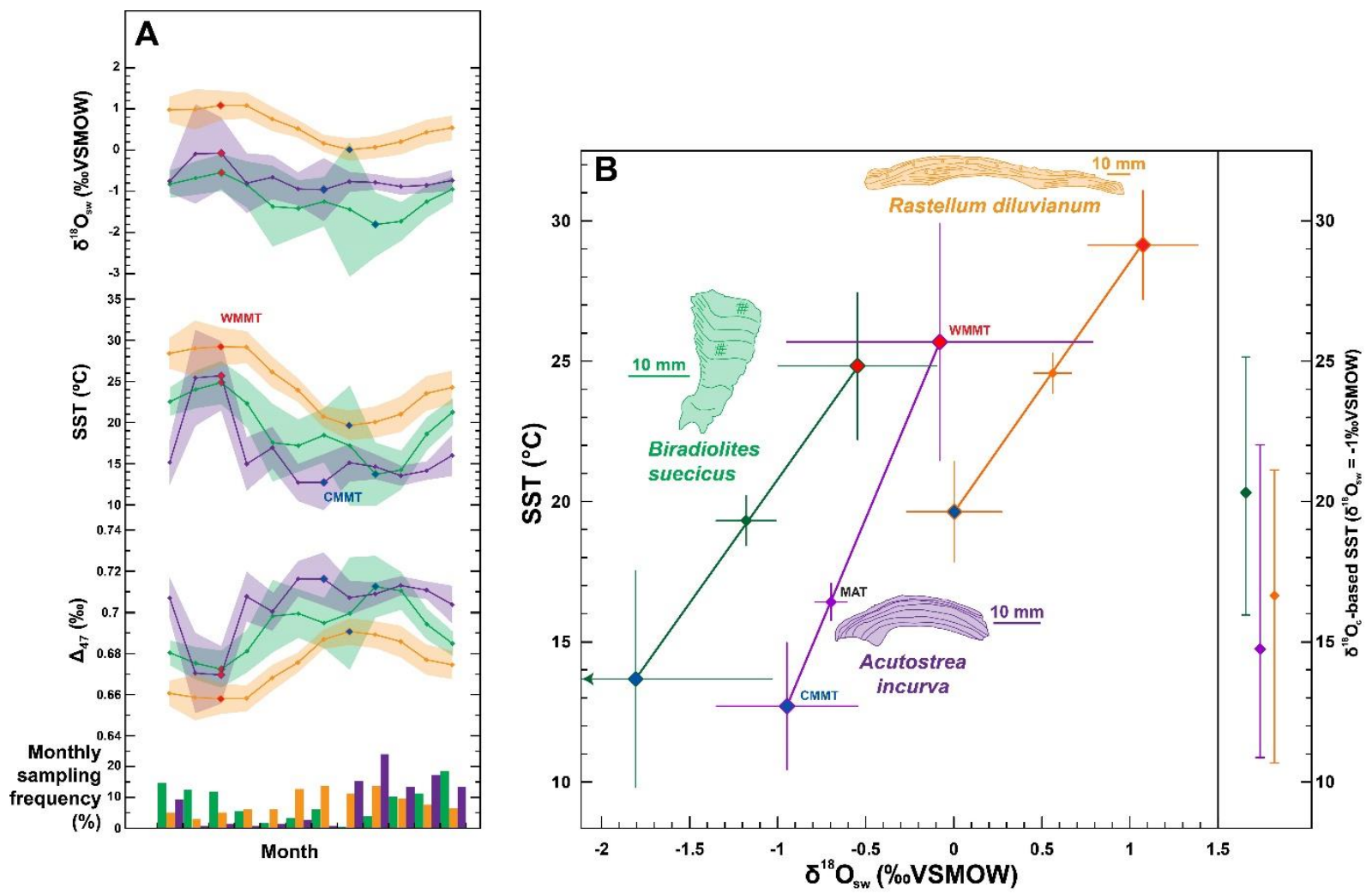

Fig. 2: Paleoseasonality reconstructions A) From bottom to top: relative monthly sampling frequencies reflecting growth rate variability (bar chart), monthly average $\Delta_{47}$, SST and $\delta^{18} \mathrm{O}_{\text {sw }}$ reconstructions from $R$. diluvianum (orange), A. incurva (purple) and B. suecicus (green). Shaded envelopes indicate $95 \%$ confidence levels. Red and blue dots respectively indicate warmest and coldest months. B) SST and $\delta^{18} \mathrm{O}_{\mathrm{sw}}$ reconstructions of warmest month (red symbols), coldest month (blue symbols) and annual average (symbols in color of specimen). Thin crosses indicate 95\% confidence level uncertainties. Vertical bars on the right indicate summer, winter and MAT estimates from $\delta^{18} \mathrm{O}_{\mathrm{c}}$ (assuming constant $\delta^{18} \mathrm{O}_{\mathrm{sw}}$ of -1\% VSMOW). Scaled cross-sections through specimens are drawn with horizontal $10 \mathrm{~mm}$ scale bars. 


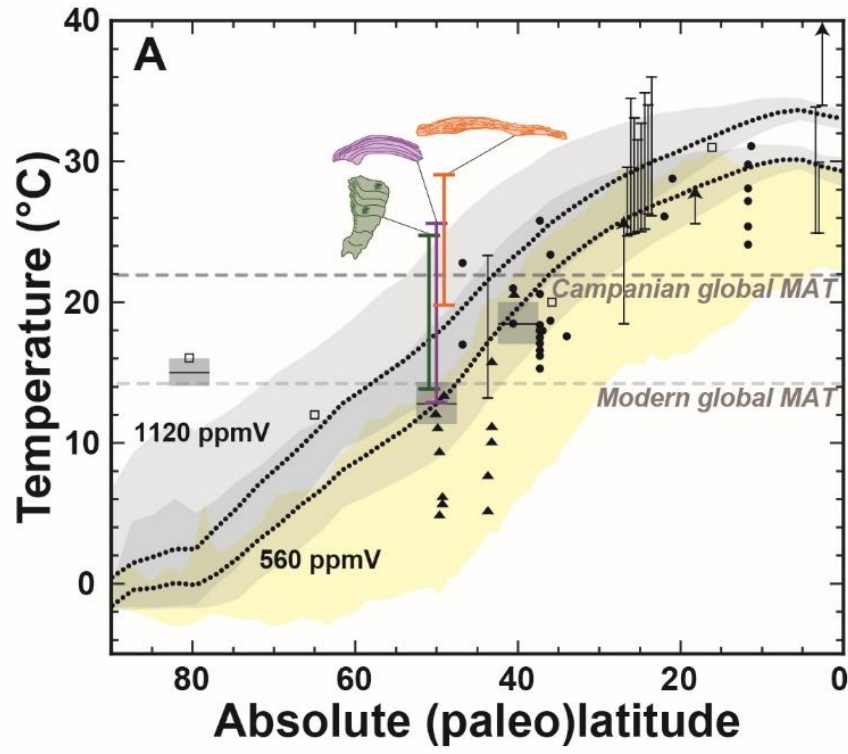

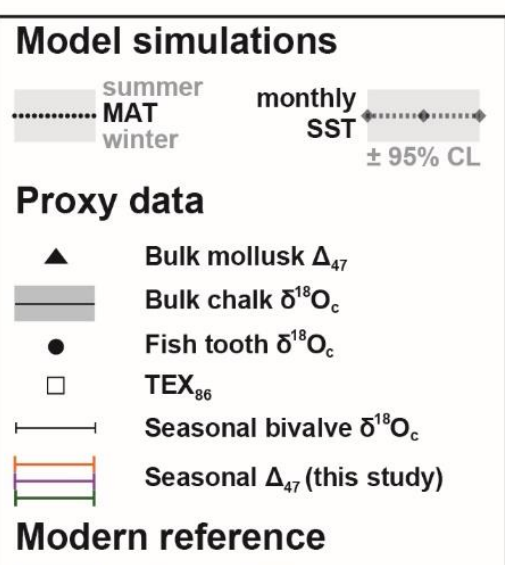

Modern SST seasonal range

Fig. 3: Comparison between model and reconstructions. A) Campanian latitudinal SST gradient with vertical orange, purple and green bars showing seasonality reconstructions and dashed black lines indicating modeled mean annual temperatures $(560 \mathrm{ppmV}=2 \times$ preindustrial and $1120 \mathrm{ppmV}=4 \times$ preindstrial $\mathrm{pCO}_{2}$ ) with grey envelopes representing seasonality. Black symbols and bars show previous SST reconstructions $s^{7,8,10,11,12,32,39,40}$. The shaded yellow envelope indicates modern seasonal SST range ${ }^{28}$. Horizontal dashed lines mark modern and Campanian global MAT. B) Monthly SST reconstructions (in orange, purple and green) and local model outputs (in grey) in the Boreal Chalk Sea. Diamonds indicate monthly SST means, with red and blue diamonds showing monthly summer and winter extremes, respectively. Shaded envelopes show 95\% confidence levels and color coding follows Fig. 2. 


\section{METHODS}

\section{Geological setting}

The bivalve specimens used in this study were obtained from the Ivö Klack (R. diluvianum), Åsen (A. incurva) and Maltesholm (B. suecicus) localities in the Kristianstad Basin in southern 349 Sweden $\left(56^{\circ} 2^{\prime} \mathrm{N}, 14^{\circ} 9^{\prime}\right.$ E; $46 \pm 3^{\circ} \mathrm{N}$ paleolatitude ${ }^{27,41}$; see Fig. 1 and Supplementary Data 7). 350 The three distinct localities contain a rich (> 200 species), well preserved Campanian rocky shore 351 fauna ${ }^{27,38}$ and were all deposited at the peak of transgression of the latest early Campanian, as 352 supported by the restriction of these deposits to the Belemnellocamax mammillatus belemnite 353 biozone and Sr-isotope chemostratigraphy ${ }^{26,38,42}$. The tectonic quiescence of the region since the

354 Late Cretaceous limited burial and promoted excellent shell preservation ${ }^{27}$. Burial of loosely 355 compacted sediments of the studied localities was limited to a maximum of 40 meters ${ }^{27}$. We can 356 therefore conclude that burial temperatures never exceeded $80^{\circ} \mathrm{C}$ and that solid-state reordering 357 did not affect clumped isotope results from these specimens ${ }^{43,44}$ (see Supplementary Methods). 358 The Kristianstad Basin represents the highest latitude location for the occurrence of rudist bivalves 359 known to date ${ }^{38}$.

\section{Materials}

Fossil $R$. diluvianum oysters were found in situ clinging to the sides of large boulders at a 363 paleodepth of $<5 \mathrm{~m}^{27}$, while the $B$. suecis rudist and $A$. incurva oysters were found in life position 364 in a deeper setting $(5-15 \mathrm{~m})$ among skeletal fragments on the paleo-seafloor ${ }^{45}$ (see Supplementary 365 Methods). The preservation of multiple specimens from this site (including the ones used here) 
$367 \mathrm{Mn} / \mathrm{Ca}$ ) analyses and ultrastructure preservation, results of which are reported in detail in ${ }^{26}$ and $^{45}$ 368 and summarized in Supplementary Methods.

370 Sampling

Powdered samples $(\sim 300 \mu \mathrm{g})$ were drilled in growth direction from polished cross sections

372 through the shell's axis of maximum growth using a Dremel ${ }^{\circledR} 3000$ rotary drill (Robert Bosch Ltd., 373 Uxbridge, UK) operated at slow rotation equipped with a $300 \mu \mathrm{m}$ wide tungsten carbide drill bit. 374 High $(\sim 100 \mu \mathrm{m})$ uniform sampling resolution was achieved by careful abrasive drilling using the 375 side of the drill parallel to the growth lines in the shell. In oyster shells, the well-preserved dense 376 foliated calcite was targeted, while in the rudist the dense outer calcite was sampled, avoiding the 377 honeycomb structure in the inner part of the outer shell layer which is more susceptible to 378 diagenetic alteration ${ }^{46}$. A total of 145 samples was obtained, from which 338 aliquots of $\sim 100 \mu \mathrm{g}$ 379 were analyzed (see Table 1).

\section{Clumped isotope analyses}

Clumped isotope $\left(\Delta_{47}\right)$ analyses were carried out on Thermo Fisher Scientific MAT253 and 253 Plus mass spectrometers coupled to a Kiel IV carbonate preparation devices. Calcite samples

384 (individual replicates of $\sim 90 \mu \mathrm{g}$ for MAT253 Plus and $\sim 150 \mu \mathrm{g}$ for MAT253) were reacted at 70 ${ }^{\circ} \mathrm{C}$ with nominally anhydrous (103\%) phosphoric acid. The resulting $\mathrm{CO}_{2}$ gas was cleaned from water and organic compounds with two cryogenic LN2 traps and a PoraPak Q trap kept at $-40{ }^{\circ} \mathrm{C}$.

387 The purified sample gases were analyzed in micro-volume LIDI mode with $400 \mathrm{~s}$ integration time against a clean $\mathrm{CO}_{2}$ working gas $\left(\delta^{13} \mathrm{C}=-2.82 \% ; \delta^{18} \mathrm{O}=-4.67 \%\right)$, corrected for the pressure

389 baseline $e^{41,42}$ and converted into the absolute reference frame by creating an empirical transfer function from the daily analyzed ETH calcite standards (ETH-1, -2, -3) and their accepted values ${ }^{49}$. 
391 All isotope data were calculated using the new IUPAC parameters following ${ }^{49}$ and $\Delta_{47}$ values

392 were projected to a $25{ }^{\circ} \mathrm{C}$ acid reaction temperature with a correction factor of $0.071 \%{ }^{22}$. Long-

393 term $\Delta_{47}$ reproducibility standard deviation was $0.04 \%$ ( $0.039 \%$ o for MAT253 Plus and $0.045 \%$ o

394 for MAT253) based on repeated measurements of $\sim 100 \mu \mathrm{g}$ aliquots of our check standard IAEA

395 C2 ( $\Delta_{47}$ of 0.719\%; measured over a 20-month period; see Supplementary Data 8 for details).

396 No statistical difference was found between results from both instruments (see Supplementary

397 Data 8). For the $\delta^{18} \mathrm{O}_{\mathrm{c}}$ compositions we applied an acid correction factor of $1.00871^{17}$ and reported

398 versus VPDB with a typical reproducibility below $0.13 \%$ ( $95 \%$ confidence level). Results were

399 combined with $\delta^{18} \mathrm{O}_{\mathrm{c}}$ data previously measured in the same shells ${ }^{26,45}$ (Supplementary Data 2) to

400 improve the confidence of seasonal age models and the temporal resolution of SST and $\delta^{18} \mathrm{O}_{\text {sw }}$

401 reconstructions.

402

403 Absolute paleoseasonality reconstructions

404

We reconstructed absolute SST seasonality by aligning $\Delta_{47}$ data relative to the seasonal cycle

405 observed in $\delta^{18} \mathrm{O}_{c}$ using an age modelling routine ${ }^{51}$ (Supplementary Data 1 and 9). Note that

406 while chronologies were based on seasonal oscillations in $\delta^{18} \mathrm{O}_{\mathrm{c}}$ records, the resulting age model

407 is not compromised by unconstrained seasonal variability in $\delta^{18} \mathrm{O}_{\mathrm{sw}}$ (see discussion in [REF20]

408 and Supplementary Methods). Since only the shape of the seasonally oscillations in $\delta^{18} \mathrm{O}_{\mathrm{c}}$ is used

409 for age modelling, age model results are independent on the absolute SST and $\delta^{18} \mathrm{O}_{\text {sw }}$ seasonality

410 and yield accurate results as long as the shape of the $\delta^{18} \mathrm{O}_{c}$ curve exhibits annual cyclicity (see ${ }^{50}$

411 and ${ }^{20}$; Supplementary Methods). We used a statistical approach to combine aliquots for $\Delta_{47-}$

412 based seasonality reconstructions. A step-by-step explanation of our $\Delta_{47}-\delta^{18} \mathrm{O}_{\mathrm{c}}$ seasonality routine

413 as well as a detailed evaluation of its precision and accuracy on a range of $\Delta 47-\delta^{18} \mathrm{O}_{\mathrm{c}}$ datasets is 
414 provided in ${ }^{20}$ and in Supplementary Methods. The number of $100 \mu \mathrm{g} \Delta_{47}$ aliquots to combine

415 into monthly SST estimates is optimized by grouping aliquots from the same month in different

416 growth years. Analytical uncertainties are propagated through this optimization procedure using

417 Monte Carlo simulations (details in Supplementary Methods and Supplementary Data 10).

418 SST's are calculated from $\Delta_{47}$ values in monthly time bins $\left(1 / 12^{\text {th }}\right.$ of the seasonal cycle) using the

419 temperature calibration by ${ }^{51}$ recalculated in ${ }^{23}$, and $\delta^{18} \mathrm{O}_{\text {sw }}$ is reconstructed from $\Delta_{47}-\mathrm{SST}$ and $\delta^{18} \mathrm{O}_{\mathrm{c}}$

420 following ${ }^{17}$ (Supplementary Methods and Supplementary Data 3). The accuracy of this

421 statistical approach for combining $\Delta_{47}$ aliquots for seasonal SST and $\delta^{18} \mathrm{O}_{\mathrm{sw}}$ reconstructions is

422 tested on a diverse group of modern datasets and evaluated in ${ }^{20}$. It is demonstrated that this method

423 achieves the ideal compromise between eliminating bias and retaining high reproducibility while

424 keeping SST and $\delta^{18} \mathrm{O}_{\text {sw }}$ reconstructions independent of the $\delta^{18} \mathrm{O}_{\mathrm{c}}$ values on which the age model

425 is based ${ }^{20}$ (see also Supplementary Methods). The clumped isotope temperature calibration by ${ }^{23}$

426 is statistically indistinguishable from the temperature relationship based on theoretical principles

427 within the temperature range discussed in ${ }^{24}$ and is the culmination of recent convergence of

428 measurement results between labs across the world and inter-lab standardization efforts ${ }^{22,49}$.

429 Seasonality is defined as the difference between the average temperatures in the warmest and

430 coldest month, while mean annual temperature (MAT) is expressed as the average of all monthly

431 temperatures, following USGS definitions ${ }^{52}$. Statistical analyses of seasonality, differences

432 between specimens and differences between data and model are summarized in Supplementary

$433 \quad$ Data 4.

434

435 Climate model 
We utilize a fully equilibrated (>11,000 model years) paleoclimate model (HadCM3L)

437 Campanian (78 Ma) simulation. Model boundary conditions (topography, bathymetry, solar

438 luminosity) for the Campanian are the same as in ${ }^{14}$. We evaluate model simulations with radiative

439 forcing $\left(p \mathrm{CO}_{2}\right)$ set to $560 \mathrm{ppmV}(2 \times$ preindustrial concentration) and $1120 \mathrm{ppmV}(4 \times$ preindustrial

440 concentration), within the range of $\mathrm{pCO}_{2}$ reconstructions for the Campanian as compiled by ${ }^{53}$, and

441 a modern astronomical configuration with dynamic vegetation. Details on the HadCM3L model

442 are provided in Supplementary Methods and in ${ }^{14}$. Local seasonal SSTs are calculated for the

443 paleorotated Kristianstad $\operatorname{Basin}^{41}\left(42.5-50^{\circ} \mathrm{N}, 7.5-15^{\circ} \mathrm{E}\right.$; Supplementary Data 5) from averages

444 of the upper ocean grid boxes in the model simulation. The model has a spatial resolution of $3.75^{\circ}$

$445 \times 2.5^{\circ}$ and uses 20 layers in ocean depth, of which the upper ocean box averages the top 10 meters

446 of the ocean. Hence the average SST of the Kristianstad Basin is biased against the shallowest

447 coastal regions of the basin, such as the locality of $R$. diluvianum ${ }^{54,55}$. For comparison, modern

448 SST data come from the National Oceanic and Atmospheric Administration ${ }^{25}$ (Supplementary

449 Data 6 and Supplementary Methods).

450

$451 \quad$ Data availability

452 Extended methods, data and scripts belonging to this study are available in the open-access

453 database Zenodo (https://doi.org/10.5281/zenodo.3865428).

454

455 METHODS REFERENCES

456 39. de Winter, N. J. et al. Tropical seasonality in the late Campanian (late Cretaceous):

457 Comparison between multiproxy records from three bivalve taxa from Oman.

458 Palaeogeography, Palaeoclimatology, Palaeoecology 485, 740-760 (2017). 
459 40. Walliser, E. O., Mertz-Kraus, R. \& Schöne, B. R. The giant inoceramid Platyceramus 460 platinus as a high-resolution paleoclimate archive for the Late Cretaceous of the Western 461 Interior Seaway. Cretaceous Research 86, 73-90 (2018).

462 41. van Hinsbergen, D. J. et al. A paleolatitude calculator for paleoclimate studies. PloS one $463 \quad$ 10, e0126946 (2015).

464 42. Christensen, W. K. Paleobiogeography and migration in the Late Cretaceous belemnite 465 family Belemnitellidae. Acta palaeontologica polonica 42, 457-495 (1997).

466 43. Fernandez, A. et al. Reconstructing the magnitude of Early Toarcian (Jurassic) warming 467 using the reordered clumped isotope compositions of belemnites. Geochimica et 468 Cosmochimica Acta (2020) doi:10.1016/j.gca.2020.10.005.

469 44. Henkes, G. A. et al. Temperature limits for preservation of primary calcite clumped 470 isotope paleotemperatures. Geochimica et Cosmochimica Acta 139, 362-382 (2014).

471 45. Sørensen, A. M., Ullmann, C. V., Thibault, N. \& Korte, C. Geochemical signatures of 472 the early Campanian belemnite Belemnellocamax mammillatus from the Kristianstad Basin 473 in Scania, Sweden. Palaeogeography, palaeoclimatology, palaeoecology 433, 191-200 $474 \quad(2015)$.

475 46. Pons, J. M. \& Vicens, E. The structure of the outer shell layer in radiolitid rudists, a 476 morphoconstructional approach. Lethaia 41, 219-234 (2008).

477 47. Bernasconi, S. M. et al. Background effects on Faraday collectors in gas-source mass 478 spectrometry and implications for clumped isotope measurements. Rapid Communications in 479 Mass Spectrometry 27, 603-612 (2013). 
48. Meckler, A. N., Ziegler, M., Millán, M. I., Breitenbach, S. F. \& Bernasconi, S. M. Longterm performance of the Kiel carbonate device with a new correction scheme for clumped isotope measurements. Rapid Communications in Mass Spectrometry 28, 1705-1715 (2014).

49. Daëron, M., Blamart, D., Peral, M. \& Affek, H. P. Absolute isotopic abundance ratios and the accuracy of $\Delta 47$ measurements. Chemical Geology 442, 83-96 (2016).

50. Judd, E. J., Wilkinson, B. H. \& Ivany, L. C. The life and time of clams: Derivation of intra-annual growth rates from high-resolution oxygen isotope profiles. Palaeogeography, Palaeoclimatology, Palaeoecology 490, 70-83 (2018).

51. Kele, S. et al. Temperature dependence of oxygen-and clumped isotope fractionation in carbonates: a study of travertines and tufas in the 6-95 $\mathrm{C}$ temperature range. Geochimica et Cosmochimica Acta 168, 172-192 (2015).

52. O’Donnell, M. S. \& Ignizio, D. A. Bioclimatic predictors for supporting ecological applications in the conterminous United States. US Geological Survey Data Series 691, (2012).

53. Foster, G. L., Royer, D. L. \& Lunt, D. J. Future climate forcing potentially without precedent in the last 420 million years. Nature Communications 8, 14845 (2017).

54. Johns, T. C. et al. The second Hadley Centre coupled ocean-atmosphere GCM: model description, spinup and validation. Climate Dynamics 13, 103-134 (1997).

55. Lunt, D. J. et al. Palaeogeographic controls on climate and proxy interpretation. Climate of the Past 12, (2016).

\section{ACKNOWLEDGEMENTS}

The authors thank Prof. Ethan Grossman and 2 anonymous reviewers for their comments that have helped improve the manuscript, as well as dr. Erin Scott for moderating the review process. 
504 NJW is funded by the Flemish Research Council (FWO; junior postdoc grant; 12ZB220N) and 505 the European Commission (MSCA Individual Fellowship; UNBIAS project 843011). NT 506 acknowledges Carslbergfondet CF16-0457. PC would like to acknowledge funding from the

507 VUB Strategic Research grant (internal). The authors would like to thank Bart Lippens for help 508 with sample preparation, Arnold van Dijk for analytical support and Anne Sørensen for helping 509 with sample collection.

\section{AUTHOR CONTRIBUTIONS}

512 The initial design of the study was conceived by NJW, NT, CVU and MZ. NJW, IAM, IJK and $513 \mathrm{MZ}$ together were responsible for clumped isotope data acquisition. NT and CVU provided 514 samples used in this study. DJL and AF ran the climate model and provided in-depth input on 515 model-data integration. NJW and PC were responsible for acquiring the funding needed for this 516 study. NJW wrote the first draft of the manuscript and revision. All authors then contributed to 517 the writing process.

520 The authors have no competing interest to declare.

\section{SUPPLEMENTARY INFORMATION}

523 All supplementary material belonging to this manuscript is deposited in the open-source online 524 database Zenodo (https://doi.org/10.5281/zenodo.3865428). 


\section{Figures}

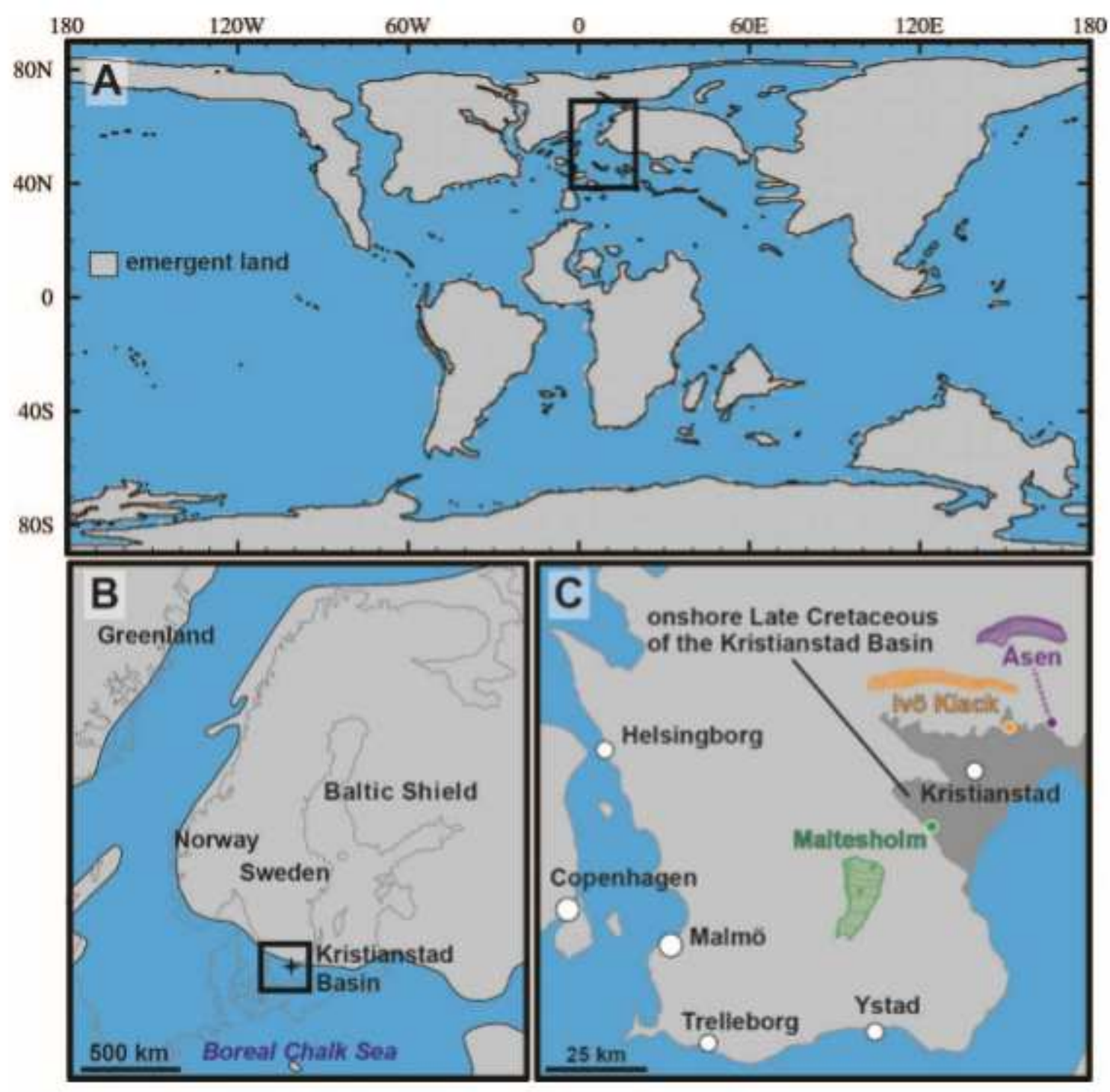

Figure 1

Campanian (78 Ma) paleogeography and geological setting A) Global paleogeography used in climate model14 B) Northern Europe, black star indicates the Kristianstad Basin C) Southern Sweden with Kristianstad Basin (in dark grey, submerged in the Campanian). Colored dots indicate the three sampled localities on the paleoshoreline with schematic representations of the species. In all maps, blue color indicates sea surface and light grey indicates emergent land. Maps B) and C) are adapted from38. Note: The designations employed and the presentation of the material on this map do not imply the expression of any opinion whatsoever on the part of Research Square concerning the legal status of any country, territory, city or area or of its authorities, or concerning the delimitation of its frontiers or boundaries. This map has been provided by the authors. 

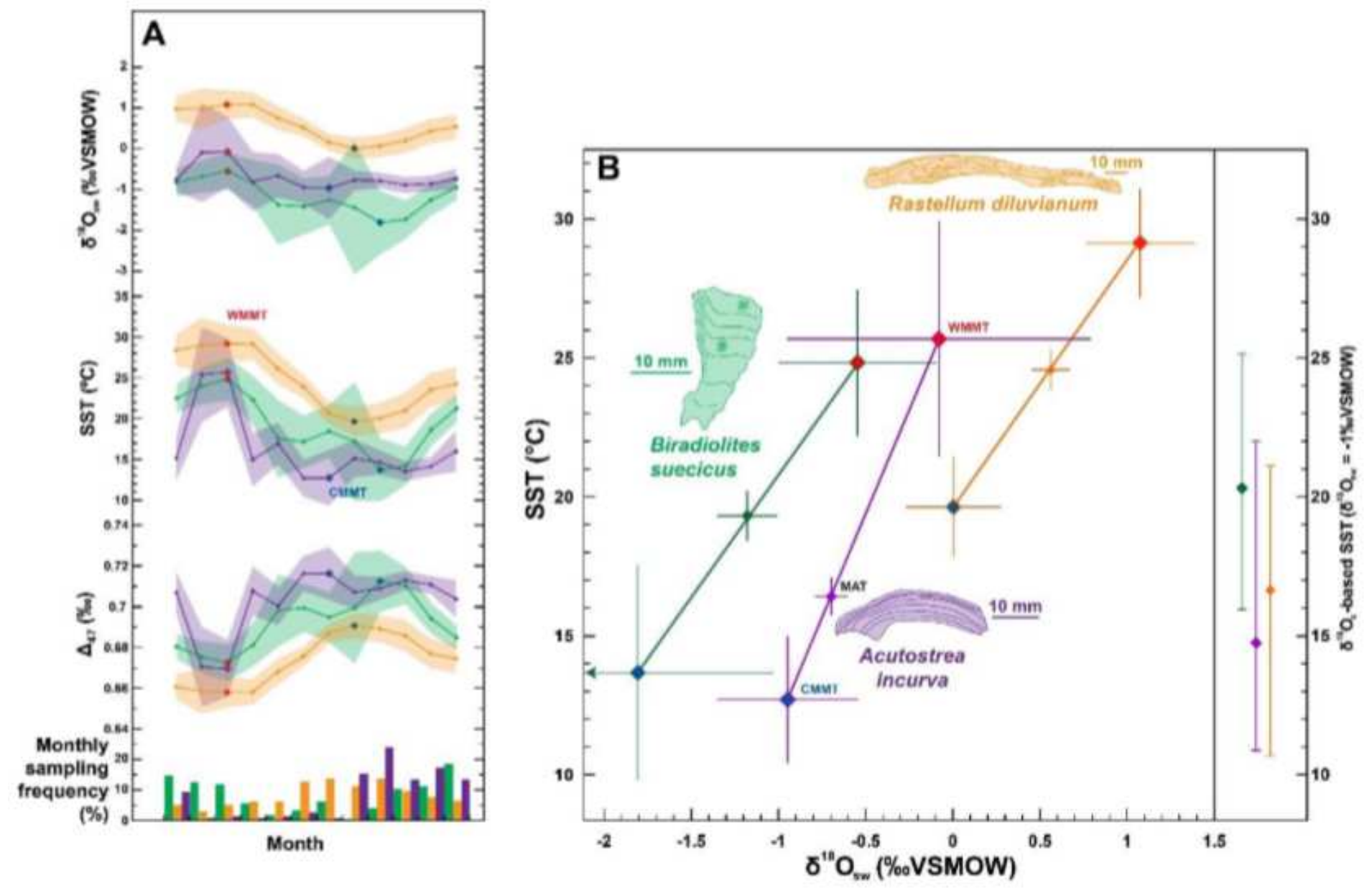

Figure 2

Paleoseasonality reconstructions A) From bottom to top: relative monthly sampling frequencies reflecting growth rate variability (bar chart), monthly average $\Delta 47$, SST and $\delta 180$ sw reconstructions from $\mathrm{R}$. diluvianum (orange), A. incurva (purple) and B. suecicus (green). Shaded envelopes indicate $95 \%$ confidence levels. Red and blue dots respectively indicate warmest and coldest months. B) SST and 8180sw reconstructions of warmest month (red symbols), coldest month (blue symbols) and annual average (symbols in color of specimen). Thin crosses indicate $95 \%$ confidence level uncertainties. Vertical bars on the right indicate summer, winter and MAT estimates from $8180 \mathrm{c}$ (assuming constant $\delta 180$ sw of $-1 \%$ VSMOW). Scaled cross-sections through specimens are drawn with horizontal $10 \mathrm{~mm}$ scale bars. 

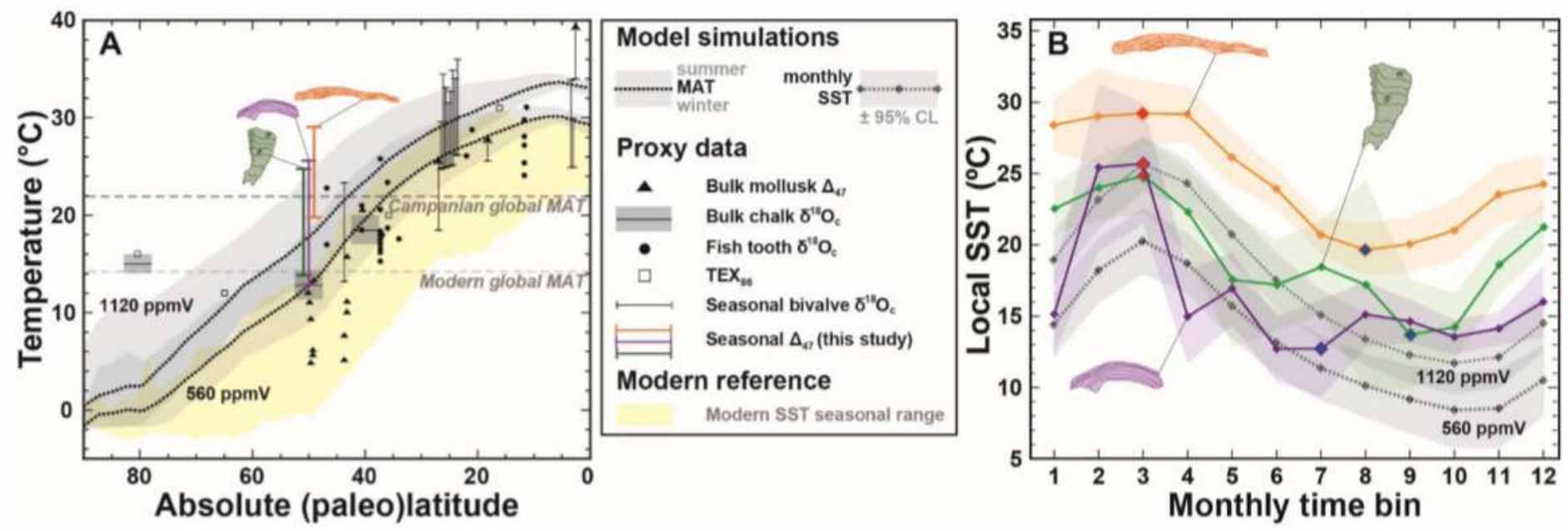

Figure 3

Comparison between model and reconstructions. A) Campanian latitudinal SST gradient with vertical orange, purple and green bars showing seasonality reconstructions and dashed black lines indicating modeled mean annual temperatures $(560 \mathrm{ppmV}=2 \times$ preindustrial and $1120 \mathrm{ppmV}=4 \times$ preindstrial pCO2) with grey envelopes representing seasonality. Black symbols and bars show previous SST reconstructions $7,8,10,11,12,32,39,40$. The shaded yellow envelope indicates modern seasonal SST range28. Horizontal dashed lines mark modern and Campanian global MAT. B) Monthly SST reconstructions (in orange, purple and green) and local model outputs (in grey) in the Boreal Chalk Sea. Diamonds indicate monthly SST means, with red and blue diamonds showing monthly summer and winter extremes, respectively. Shaded envelopes show 95\% confidence levels and color coding follows Fig. 2.

\section{Supplementary Files}

This is a list of supplementary files associated with this preprint. Click to download.

- SupplementaryTextNatCommEarthEnv.pdf 